\section{CNS Spectrums}

www.cambridge.org/cns

\section{Letter to the Editor}

Cite this article: Marazziti D, and Stahl SM (2022). Response to the Letter to the Editor "Psychiatry's undeclared identity crisis in a changing world" by Richard Skaff. CNS Spectrums 27(5), 555-556.

https://doi.org/10.1017/S1092852921000559

Received: 27 April 2021

Accepted: 12 May 2021

\section{Key words:}

Changing world; psychiatry; novel issues; climate change; pollution; migrations; Covid-19 pandemic

\section{Author for correspondence:}

*Donatella Marazziti, MD

Email: dmarazzi@psico.med.unipi.it (c) The Author(s), 2021. Published by Cambridge University Press.

\title{
Response to the Letter to the Editor "Psychiatry's undeclared identity crisis in a changing world" by Richard Skaff
}

Donatella Marazziti ${ }^{1,2 *}$ (1) and Stephen M. Stahl ${ }^{3,4,5}$

\begin{abstract}
${ }^{1}$ Department of Clinical and Experimental Medicine, University of Pisa, Italy, ${ }^{2}$ Unicamillus-Saint Camillus University of Health Sciences, Rome, Italy, ${ }^{3}$ Department of Psychiatry, University of California, San Diego, California, USA, ${ }^{4}$ Neuroscience Education Institute, San Diego, California, USA, and ${ }^{5}$ Department of Psychiatry, University of Cambridge, Cambridge, United Kingdom
\end{abstract}

We thank very much Dr. Richard Skaff for his comments to our editorial published in the February 2021 issue of CNS Spectrums, since we do hope that this might perhaps generate a wider debate on the current state of Psychiatry and where it will be heading in the next decades.

Within the frame of a short editorial, we attempted to highlight what are, according to us, the most pressing and unavoidable problems deriving form an evolving world that current psychiatry has to cope with. Indeed, the focus of our considerations was not on why psychiatry is what it is nowadays, but what should de done to reinforce the relationships between psychiatric research and practice in a rapidly changing world requiring urgent responses and rapid implementation of innovative approaches. The COVID19 pandemic is the latest and unprecedented catastrophe scrambling the health systems wordwide that even more highlights, on one side, the limits of the systems themselves, but also the urgency of effective and fast therapeutic strategies.

We listed the major domains of psychiatric interests that should be considered and addressed, while providing preliminary suggestions of potential interventions that cannot be exhaustive.

In any case, we do not agree with the pessimistic view of Dr. Skaff that some problems, such as natural or human-made disasters should not be approached because "...adapting a discipline such as psychiatry" to "..effectively deal with these enormous challenges is daunting..." The author seems to neglect that extreme calamities might create novel problems of psychiatric interest. There is an increasing literature on the short- or long-term psychological/psychiatric consequences of climate change, natural disasters, air pollution, and migration ranging from mild stress effects to full-blown psychiatric disorders. ${ }^{2-5}$ Since mental disorders associated with climate change are still poorly understood, even new terms, such as "eco-anxiety" and "solastalgia" were coined to define some new psychological conditions associated with climate change. ${ }^{6,7}$ The term "eco-anxiety" denotes the stress that a subject experiences in perceiving nature as fragile and vulnerable, as well as the frustration of being unable to face such a dramatic change. ${ }^{6,8}$ The term "solastalgia" labels a psychic state in which people, often immigrants, do not recognize as familiar the environment where they live and are unable to adapt to. ${ }^{7}$

Again, increasing evidence shows the negative influence of SARS-COV2 pandemic on the worldwide population's psychological wellbeing, such as feelings of anguish and uncertainty, fear of death, demoralization, anxiety, insomnia, distorted perceptions, dangerous behaviors, including increased use of alcohol and substances, as well as internet addiction conducts, amongst a large part of adults, children, and adolescents everywhere. ${ }^{9-11}$ Some studies, primarily in small series, investigated neuropsychiatric symptoms and/or disorders directly in COVID-19 patients. Approximately $20 \%$ to $40 \%$ of patients suffered from neuropsychiatric symptoms, including delirium, insomnia, anxiety, and depression. ${ }^{11,12}$ Finally, based on evidence from previous pandemics, the COVID-19 pandemic may also increase the risk for suicidal ideation and behavior and psychiatric symptoms, especially depression and trauma-related disorders. According to the report of the Well Being Trust (WBT) and the Robert Graham Center for Political Studies in Family Medicine and Primary Care, an additional 75000 Americans could die from suicide, drugs, or alcohol abuse, mainly in connection with the high unemployment rate caused from the pandemic. ${ }^{13-15}$

Not surprisingly, increasing recent observations authorize to hypothesize that climate change, environmental pollution, COVID-19 pandemic and mental health might be intertwined. ${ }^{16}$

Instead of focusing on the past errors that have promoted "negative public notions, speculations, and uncertainties," and have "besieged psychiatry", as psychiatrists we should also recall the extraordinary achievements reached by both neuroscientific and psychopharmacological research that provides therapeutic tools to treat in a more or less tailored way a large part of our 
patients. Prescribing the right drugs to the right patients does not mean to be partners of pharmaceutical companies, and uncertainties about the "real" mechanism of action of the majority of available psychotropic compounds, should never prevent us from prescribing them: this would be really unethical!

However, we agree with Dr. Skaff, that this cannot be enough and there is a lot to do to improve psychiatric practice and to render it more flexible and suitable to run in parallel with the requests. and issues deriving from the evolving environment. Last, but not least, the renewed interest and funding of space missions to Mars and beyond represent another hot issue to psychiatry, given the available information of long-term psychological and psychopathological consequences on astronauts.

It is evident that preventing and treating both old and novel psychopathological conditions require integrated interventions involving focused educational programs to increase awareness and reduce social stigma coupled with a deep reshaping of environmental policy, societies and medical practice.

Disclosures. Donatella Marazziti has no disclosures, and she has no affiliation with or financial interest in any organization that might pose a conflict of interest. Stephen M. Stahl, MD, PhD, Dsc (Hon.) is an Adjunct Professor of Psychiatry at the University of California San Diego, Honorary Visiting Senior Fellow at the University of Cambridge, UK and Director of Psychopharmacology for California Department of State Hospitals. Over the past 40 months (January 2018 to April 2021) Dr. Stahl has served as a consultant to Acadia, Adamas, Alkermes, Allergan, Abbvie, Arbor Pharmaceutcials, AstraZeneca, Avanir, Axovant, Axsome, Biogen, Biomarin, Biopharma, Celgene, Concert, ClearView, DepoMed, EnVivo, EMD Serono, Eisai Pharmaceuticals, Ferring, Forest, Forum, Genomind, Innovative Science Solutions, Impel, Karuna, NeuroPharma, Intra-Cellular Therapies, Ironshore Pharmaceuticals, Janssen, Jazz, Lilly, Lundbeck, Merck, Neos, Novartis, Noveida, Otsuka, Perrigo, Pfizer, Pierre Fabre, Relmada, Reviva, Sage Therapeutics, Servier, Shire, Sprout, Sunovion, Takeda, Taliaz, Teva, Tonix, Tris Pharma, Trius, Vanda, Vertex, and Viforpharma; he has been a board member of RCT Logic and Genomind; he has served on speakers bureaus for Acadia, Forum, Genentech, Janssen, Lundbeck, Merck, Otsuka, Servier, Sunovion, Takeda, and Teva, and he has received research and/or grant support from Acadia, Alkermes, AssureX, Astra Zeneca, Arbor Pharmaceuticals, Avanir, Axovant, Biogen, Braeburn Pharmaceuticals, BristolMyer Squibb, Celgene, CeNeRx, Cephalon, Dey, Eli Lilly, EnVivo, Forest, Forum, GenOmind, Glaxo Smith Kline, Intra-Cellular Therapies, ISSWSH, Janssen, JayMac, Jazz, Lundbeck, Merck, Neurocrine, Neuronetics, Novartis, Otsuka, Pfizer, Reviva, Roche, Servier, Shire, Sprout, Sunovion, TMS NeuroHealth Centers, Takeda, Teva, Tonix, and Vanda.

\section{References}

1. Marazziti D, Stahl SM. Novel challenges to psychiatry from a changing world. CNS Spectr. 2021;26(1):3-4. doi:10.1017/S1092852919001858.

2. Reifels L, Bassilios B, Spittal MJ, et al. Patterns and predictors of primary mental health service use following bushfire and flood disasters. Disaster Med Public Health Prep. 2015;9(3):275-282. doi:10.1017/dmp.2015.23.

3. Blanc J, Spruill T, Butler M, et al. Is resilience a protective factor for sleep disturbances among earthquake survivors? Sleep. 2019;42:A356-A356. doi 10.1093/sleep/zsz067.883.

4. Hayes K, Blashki G, Wiseman J, et al. Climate change and mental health: risks, impacts and priority actions. Int J Ment Health Syst. 2018;12:28. doi 10.1186/s13033-018-0210-6.

5. Ursano RJ, Morganstein JC, Cooper R. Resource document on mental health and climate change. APA Resource Document. 2017.

6. Arcanjo M. Eco-Anxiety: Mental Health Impacts of Environmental Disasters and Climate Change. New York: Climate Institute; 2019.

7. Albrecht G, Sartore GM, Connor L, et al: The distress caused by environmental change. Austr Psychiatry. 2007;15(Suppl 1):S95-98. doi:10.1080/ 10398560701701288.

8. Gifford E, Gifford R. The largely unacknowledged impact of climate change on mental health. Bull Atom Sci. 2016;72:292-297. doi:10.1080/ 00963402.2016.1216505.

9. Tang $\mathrm{W}, \mathrm{Hu} \mathrm{T}, \mathrm{Hu} \mathrm{B}$, et al. Prevalence and correlates of PTSD and depressive symptoms one month after the outbreak of the COVID-19 epidemic in a sample of home-quarantined Chinese university students. J Affect Dis. 2020;274:1-7. doi:10.1016/j.jad.2020.05.009.

10. Tian F, Li H, Tian S, et al. Psychological symptoms of ordinary Chinese citizens based on SCL-90 during the level I emergency response to COVID-19. Psychiatry Res. 2020;288:112992-112992. doi:10.1016/j.psychres.2020.112992.

11. McGinty EE, Presskreischer R, Han H, et al. Psychological distress and loneliness reported by us adults in 2018 and April 2020. JAMA. 2020;324 (1):93-94. doi:10.1001/jama.2020.9740.

12. Holmes EA, O'Connor RC, Perry VH, et al. Multidisciplinary research priorities for the COVID-19 pandemic: a call for action for mental health science. Lancet Psychiatry. 2020;7(6):547-560. doi:10.1016/s2215-0366(20)30168-1.

13. Bo H.-X, Li W, Yang Y, et al. Posttraumatic stress symptoms and attitude toward crisis mental health services among clinically stable patients with COVID-19 in China. Psychol Med. 2020;27 1-2. doi:10.1017/S0033291720000999.

14. Brooks, M. US 'deaths of despair' from COVID-19 could top 75,000, experts warn; 2020.

15. Petterson SW, John M, Miller BF. Projected deaths of despair during the coronavirus recession; 2020. Articles, Abstracts, and Reports. 3054. https:// digitalcommons.psjhealth.org/publications/3054.

16. Marazziti D, Cianconi $\mathrm{P}$, Mucci F, et al. Climate change, environmental pollution, Covid-19 pandemic and mental health. Sci Total Environ. 2021; 773:145182. doi:10.1016/j.scitotenv.2021.145182. Epub 2021 Jan 21. PMID: 33940721; PMCID: PMC7825818. 